\title{
Multicriterial Evaluation of the Transport and Logistic System of the Moscow Region
}

\author{
Vasily Demin ${ }^{1}$, and Alexey Terentyev ${ }^{1 *}$ \\ ${ }^{1}$ Moscow Automobile and Road Construction State Technical University (MADI), 64 Leningradsky \\ prosp., 125319, Moscow, Russia
}

\begin{abstract}
The article deals with the direction of solving complex problems of interaction between the elements of the transport and logistics system of the Moscow region as a complex structure of management methods in multicriteria systems and technologies for monitoring the quality of processes. The control method should optimize the system parameters, and control technologies (radio frequency cargo identification) implement feedback in the system.
\end{abstract}

\section{Introduction}

The analysis of structure of costs of functioning of the transport and logistics system (TLS) of the region shows that its specific indicators significantly exceed values of transport and logistic similar systems in developed the countries of the world. Among basic reasons such condition of system it is possible to note: poor quality of road and logistic infrastructure, lack of systems of optimum distribution of traffic and material flows, low level of the technology solutions applied in the industry. The effective directions of the solution of the specified problems is: development of evidence-based methodology of optimization of the organization of work of TLS of the region; implementation of the latest electronic developments in technology process of control of a condition of system [1-5].

TLS of the Moscow region represents set of the following elements: producers of raw materials and materials, the logistic centers, producers of products, warehouses of distributors, shopping facilities, consumers, objects of a recycling and the cargo transport which is carrying out a link role. From the point of view of forming of expenses, resourceand machining contents, connection processes between elements of a transport and logistic chain are most important: between the cargo forming point (which producers of raw materials and materials treat) and cargo transport; between cargo transport and the producer of finished goods; between the producer of finished goods and the logistic center, etc. Interaction between elements of a transport and logistic chain and freight vehicles happens through points of loading and unloading, sites of an expedition and acceptance, i.e. through terminal and warehouse infrastructure [6-7].

\footnotetext{
*Corresponding author: aleksej.terentev.67@,bk.ru
} 


\section{Theory}

The result of the analysis of functioning of elements of a transport and logistic complex of the Moscow region shows that all its main links (objects of terminal and warehouse infrastructure and cargo transport) represent complex probabilistic systems. Terminal and warehouse objects and cargo transport have a large number of the characteristics and parameters allowing to qualify them as complex technical and economic systems with the statistical and dynamic parameters of functioning changing under the influence of external and internal factors, that is borders of this system are defined by a large number of factors of the conditions of the external environment (CEE), therefore, big dimension and order of solvable tasks. Systematization of the organization of work of TLS demands development of methodology of assessment of the criteria allowing to optimize process management in systems.

The choice of entrance and output flows, level of their aggregation and mathematical modeling of management personnel in (TLS) of the Moscow region has to be carried out with respect for the following principles: entrance and output flows on its borders were elementary, and the criteria used at establishment of borders of system are identified and proved by a scope of the device of the solution of the created tasks. The main methods of the solution of multicriteria tasks can conditionally be reduced in three groups [8-9]:

- Data of multicriteria tasks to one-criteria by use of compound criteria or the principle of a minimax (maximin).

- Transition to higher level in a hierarchical control system.

- Definition of a set of effective plans (Pareto's great number).

The first group of methods based on use of compound criteria in most cases isn't objective as data of multicriteria tasks to one-criteria are carried out with their help artificially, without attempt to remove uncertainty. Here different approaches are observed.

Sometimes maximize the sum of criteria:

$$
K=\sum_{t=1}^{m} k_{i} \rightarrow \max
$$

or sometimes their work:

$$
K=\prod_{i=1}^{m} k_{i} \rightarrow \max
$$

In certain cases, in compound criteria use "weight" coefficients. for example,

$$
K=\sum_{i=1}^{m} C_{i} k_{i} \rightarrow \max
$$

where $C_{i}$-"weight" (importance) of an indicator of efficiency

If a part of criteria needs to be maximized (for example, the first q of criteria), and remained $(\mathrm{m}-\mathrm{q})$ of criteria should be minimized, then use fraction:

$$
K=\frac{\prod_{i=1}^{q} k_{i}}{\prod_{i=q+1}^{m} k_{i}} \rightarrow \max .
$$

There are also other ways of formation of compound criterion. All of them have common fault: when using such criteria, the lack of one criterion can be compensated for the account of another. For example, maximizing the sum of criteria, it can turn out that one of them will have small value, and another big. And though their sum is enough will be bike, the received decision can't be considered good. 
The second group including different methods of transition to higher level of management is free from noted shortcoming. Really, at this approach there is an opportunity to specify necessary information and to objectively choose the only (main) indicator of efficiency. But practical use of methods of transition to higher level of management often is difficult.

All management processes surrounding us are representable in the form of multi-level hierarchical system. At each level the problems of the criteria are solved. Information developed on $(k)$ level arrives on $(k+1)$ the level where it is used for the solution of other tasks of other criteria, etc. Upon transition from level to level the number of solvable tasks is, as a rule, reduced, but their importance and complexity considerably increases. Criteria of problems of $(k)$ of level have to be agreed with interests $(k+1)$ the level of management. This circumstance often helps at development of recommendations in the conditions of a multicriteria. This method of the solution of multicriteria tasks by transition to higher level of management is the most radical solution of the problem of a multicriteria. However, implementation of this method is connected often with considerable difficulties because not always, having lifted to higher level, it is possible to formulate and solve the corresponding one-criteria optimization problem $[10,11]$.

Methods of definition of a set of effective plans (Pareto's great number) forming the third group allow not to consider all noncompetitive options of actions, and to concentrate the attention only to the most reasonable. In other words, use of these methods gives an objective opportunity for the subjective choice of the decision [11]. In this case fundamental difference of hierarchy of functions of a control system is, removal at one level of several complex criterion of quality of TLS (figure 1) will be. At the same time the number of levels of hierarchy remains invariable (the flexibility of system remains invariable), but for preservation of initial parameters of management of system the multicriteria task requiring the analytical solution forms $[12,13]$.

Implementation of the provided scheme allows to create the uniform chain of deliveries consisting of elements of a production cycle of a warehouse complex of the sender, supplier and delivery of products, evaluated by a complex of independent criteria. An integral part of effective work of a complex system is obligatory availability of technologies of control of a condition of parameters and indicators of the studied processes (sets of consistently carried out operations on finishing goods of the manufacturing enterprises through the shopping, distributor and logistic centers to end users). Communication with uniform information center (server) of a chain will allow to transfer and obtain timely information that in turn will make available operational planning by all participants of process, including at emergence of changes and failures on certain sites of a chain $[14,15]$.

The regulations of use of systems of radio-frequency identification taking into account technology restrictions of use of radio transponders and a readout equipment can be developed for each of the listed links of a transport and logistic chain, levels of the radiofrequency ranges applied to each chain link are allocated. 


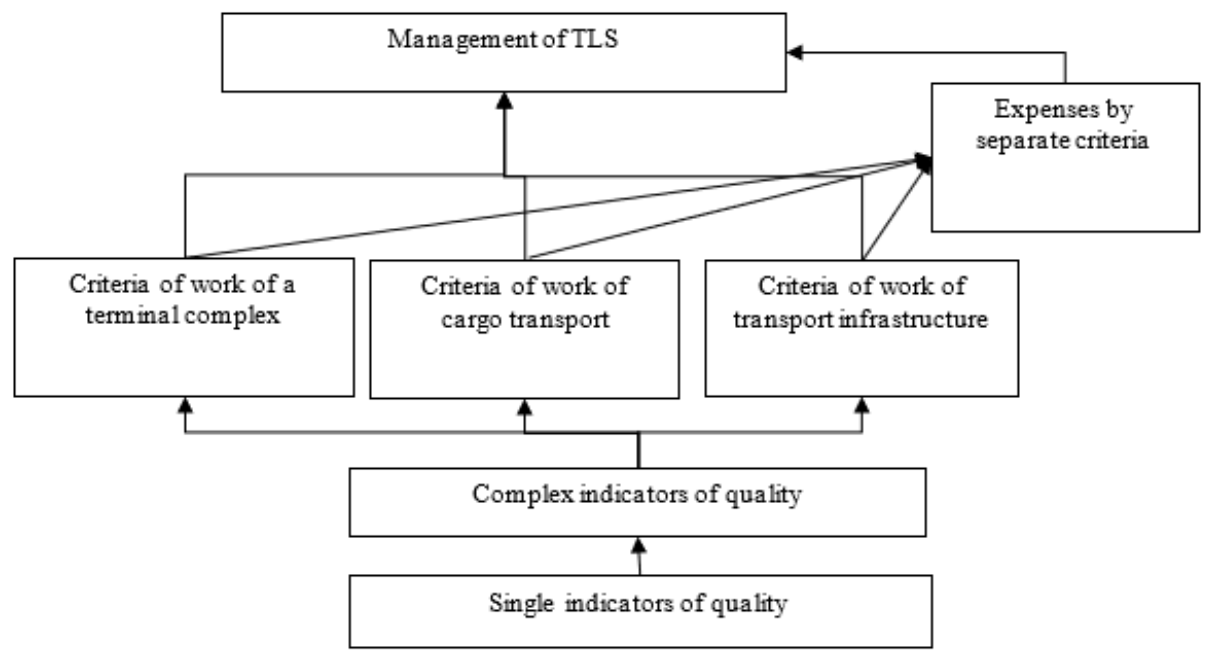

Fig. 1. Decomposition of hierarchy of structure of TLS.

In particular, data on the movement of a load at first are read out from the RFID transponder of the cargo CU, and then arrive on the region server for the further analysis and forming of the summarized information on a condition of a load for the producer and the receiver. On the basis of information on the movement of loads received from RFID complexes the forecast of movement of freight vehicles is formed, freght traffics on the region are traced, arrival time of the vehicle to the receiver is predicted. From the region server information on location of a load and the forecast of its arrival is transferred to the receiver. The optimum route forms taking into account change of a road situation, in real time. Use of systems of radio-frequency identification allows to monitor movement of products also on the warehouse or shopping facility, etc.

\section{Conclusion}

It is possible to note that the analytical solution of a multicriteria problem of optimization of work of TLS in total using as indicators of feedback of the data received by means of radiofrequency technologies of identification will give positive effect in three directions: economic, technology and service.

\section{References}

1. A.V. Potatoes, V.A. Demin, I.I. Kutuzov, Development of optimum transport and warehouse system of the company, its creation and optimization//The Integrated logistics. No. 1. - Page 5-11. (2010)

2. The investment program of the Moscow region "Development of a transport and logistics system in the Moscow region in 2011-2015". (2011)

3. The national standard of the Russian Federation of GOST P ISO 17363-2010 "Application of radio-frequency identification (RFID) in a chain of deliveries. Cargo containers". (2010)

4. National standard of the Russian Federation GOST P ISO/MEK 15963-2011

"Information technologies. Radio-frequency identification for management of objects.

Unique identification of radio-frequency tags". (2011) 
5. National standard of the Russian Federation GOST P ISO/MEK 19762-3-2011 "Information technologies. Technologies of automatic identification and data collection (AISD). The harmonized dictionary. Part 3. Radio-frequency identification (RChI)". (2011)

6. Subprogram "Transport and logistics system" of the state program of the Moscow region "Development and functioning of a road and transport complex" of 2014-2018.

7. Sandip Lahiri. RFID. Guide to implementation. - KUDITs-Press publishing house, 312 pages. (2007)

8. A.V. Terentyev, B.D. Prudovsky, Methods of definition of a great number of Pareto in some problems of linear programming. Notes of Mining institute. Volume 211. - SPb.: National mineral and raw university "Gorny", Page 89-90 (2015)

9. A.V. Terentyev, Multicriteria indicator of quality of the car. Messenger of civil engineers. - SPb: St. Petersburg state architectural and construction university, 1(48), Page 201-204. (2015)

10. B.D. Prudovskiy, A.V. Terentiev, Investigation methods for "current repairs labourintensiveness" factor for a vehicle. Life Science Journal. T. 11. № 10s. p. 307-310. (2014)

11. A.V. Terentiev, T.A. Menukhova, Economics and society in the era of technological changes and globalization the methodology of the operating cost accounting in identifying mileage of efficient motor vehicle operation. International Journal of Economics and Financial Issues. T. 5. № 3 S. p. 183-186. (2015)

12. S.A. Evtyukov, A.V. Terentyev, G. Ginzburg, Methodology of management of rational life cycle of the car. World of transport and technological machines. 2017. No. 1 (56). Page 3-10

13. A. Kapustin, A. Terentiev, Rational Lifetime of a Vehicle in Terms of Ensuring Security of Its Design, A. Kapustin, A. Terentiev, Transportation Research Procedia 20 254 - 260. https://authors.elsevier.com/sd/article/S2352146517300716. (2017)

14. A.V. Terentyev, I.V. Tarasov, V.A. Terentyeva, Hierarchy of a control system of rational life cycle of cars. Economy and management of control systems. - Voronezh: LLC Nauchnaya kniga Publishing House publishing house, 4(22) - Page 46-50 (2016)

15. A.V. Terentyev, A.A. Kapustin Assessment of quality of the car. Notes of Mining institute. Volume 219 - SPb.: National mineral and raw university "Gorny", Page 449454 (2016) 